\title{
Robotic gastric mobilization in robotic minimally invasive esophagectomy
}

\author{
Shigeru Tsunoda, Kazutaka Obama, Tatsuto Nishigori, Shigeo Hisamori, Yoshiharu Sakai \\ Department of Surgery, Graduate School of Medicine, Kyoto University, Kyoto, Japan \\ Correspondence to: Shigeru Tsunoda, MD, PhD, FACS. Department of Surgery, Graduate School of Medicine, Kyoto University, 54 Kawahara-cho, \\ Shogoin, Sakyo-ku, Kyoto 606-8507, Japan. Email: tsunoda@kuhp.kyoto-u.ac.jp. \\ Provenance and Peer Review: This article was commissioned by the editorial office, fournal of Thoracic Disease. The article did not undergo external peer review. \\ Comment on: Na KJ, Park S, Park IK, et al. Outcomes after total robotic esophagectomy for esophageal cancer: a propensity-matched comparison \\ with hybrid robotic esophagectomy. J Thorac Dis 2019;11:5310-20.
}

Submitted Feb 18, 2020. Accepted for publication Mar 16, 2020.

doi: $10.21037 /$ jtd.2020.03.124

View this article at: http://dx.doi.org/10.21037/jtd.2020.03.124

After having been first reported in 1992 by Cuschieri et al. (1), minimally invasive esophagectomy (MIE) has since undergone some innovation, such as the introduction of the prone position (2) and surgical robots.

Retrospective studies have well documented the benefits of MIE in thoracic procedures, including better shortterm outcomes such as reduced intraoperative blood loss and less postoperative pulmonary complications $(3,4)$. However, few studies have provided level 1 evidence. The TIME trial, which compared purely thoracoscopic (prone position) plus laparoscopic total MIE (TLME) and totally open esophagectomy $(\mathrm{OE}+\mathrm{OG})$ by maximizing the difference in surgical trauma, successfully showed reduced postoperative pulmonary complications (5) at the cost of longer operative time. Although both groups had similar long-term oncologic outcomes (6), the results were not convincing due to the relatively small sample size (59 vs. 56 cases, respectively). To confirm whether thoracoscopic esophagectomy was indeed not inferior to open esophagectomy in overall survival, a Japanese phase III trial (JCOG1409) is currently ongoing (7).

When subdividing MIE into thoracoscopy (TE)/ thoracotomy (OE) and laparoscopy (LG)/laparotomy (OG), a laparoscopic abdominal phase with an open thoracotomy was proven to be more beneficial compared to (totally) open esophagectomy as observed in the MIRO trial (8), which showed that hybrid MIE, a laparoscopic abdominal phase with an open thoracotomy, had better perioperative outcomes compared to open esophagectomy, with both having comparable long-term oncologic outcomes.

With regard to robotic surgery, early adopters of robotic esophagectomy during the early first decade of the 2000s used the first generation of the da Vinci surgical robotic system (DVSS) (9-12). Initially, robot-assisted MIE (RAMIE) mainly started by using the robot for thoracic part. At that time, robotic assistance was believed to be more beneficial to overcome the difficulties of conventional thoracoscopic surgery, such as instrumental conflict with the rib in narrow intercostal spaces or an instrumental axis orthogonal to the dissection axis, which is parallel to the esophagus. Thereafter, robotic assistance was gradually introduced to gastric mobilization. However, robotic gastric mobilization (RG) is a technically demanding procedure given that a single robotic arm needs to maintain exposure of the greater curvature, which can be done by assistants using two forceps during conventional laparoscopy.

Although growing evidence has been available for RAMIE, only one prospective randomized controlled trial, named the ROBOT trial, has compared robotic esophagectomy (RE) plus laparoscopic gastric mobilization (LG) and totally open esophagectomy (OE plus OG) (13). Accordingly, the results of the aforementioned trial showed that RAMIE promoted significantly lesser pulmonary complications ( $32 \%$ vs. $58 \%$ ) and cardiac complications (47\% vs. $22 \%$ ), lesser intraoperative blood loss, lower postoperative pain scores, faster functional recovery, and better quality of life compared to open esophagectomy. However, the study design of the ROBOT trial resembled 
that of the TIME trial, which maximized the difference in surgical trauma. Therefore, whether the favorable shortterm outcomes of RAMIE can be ascribed to the benefit of RE over OE or LG over OG cannot be clearly determined. Moreover, the additional effects of a robotic abdominal procedure on the robotic thoracic procedure remains unknown.

In the 2019 Fournal of Thoracic Disease, $\mathrm{Na}$ and colleagues reported the results of a propensity-matched comparison between total-RAMIE (T-RAMIE), RE plus robotic gastric mobilization (RG), and hybrid-RAMIE (H-RAMIE), RE plus OG (14). Among a total of 214 patients who underwent RAMIE in Seoul National University Hospital from 2008 to 2018, propensity score matching resulted in two equal groups of 49 patients to compare short-term and long-term outcomes. Regarding short-term outcomes, T-RAMIE depicted a comparable 90 -day mortality rate with H-RAMIE ( $0 \%$ vs. $6.1 \% ; \mathrm{P}=0.083)$. Moreover, the incidence of total ( $63.3 \%$ vs. $63.3 \% ; \mathrm{P}=1.000)$, abdominal (8.2\% vs. $14.3 \% ; \mathrm{P}=0.366)$, and respiratory complications (10.2\% vs. $10.2 \% ; \mathrm{P}=1.000)$ did not differ, while the number of retrieved abdominal lymph nodes was equivalent (12.4 \pm 9.0 vs. $12.3 \pm 8.9 ; \mathrm{P}=0.992)$. The 2 -year overall survival rate (86.2\% in T-RAMIE $v s .77 .6 \%$ in H-RAMIE; $\mathrm{P}=0.150$ ) and recurrence-free survival (76.6\% in T-RAMIE $v s .62 .2 \%$ in H-RAMIE; $\mathrm{P}=0.280$ ) were comparable between both groups. Hence, they concluded that RG might be a safe alternative to OG when accompanied with RE. However, important outcomes, such as intraoperative blood loss, operative time, and pain scores, were not documented. Thus far, it remains unclear whether T-RAMIE exhibits real clinical benefit over H-RAMIE.

In the surgical arm of the Japanese prospective multicenter trial JCOG0502, a four-arm prospective comparative study of esophageal resection with definitive chemoradiotherapy for T1bN0 esophageal squamous cell carcinoma, laparoscopy failed to further decrease postoperative pulmonary complications compared to laparotomy following thoracoscopic esophagectomy, while the thoracoscopic approach significantly decreased postoperative pulmonary complications compared to open thoracotomy (TE $15.8 \%$, OE $30.3 \% ; \mathrm{P}=0.015$ ). This was speculated to have been caused by the considerably dominant preventive effects of thoracoscopy, which masked that of laparoscopy (15).

Yang and colleagues conducted a propensity-matched comparison between robotic McKeown esophagectomy
(RME) and TLME (16) and found that RME was associated with a shorter operating time (244.5 vs. $276.0 \mathrm{~min} ; \mathrm{P}<0.001)$, shorter thoracic duration (85.0 vs. $102.9 \mathrm{~min} ; \mathrm{P}<0.001$ ), and lower conversion rate in thoracic part $(0.7 \%$ vs. $5.9 \%$; $\mathrm{P}=0.001)$. Although the count of harvested total and thoracic lymph nodes was similar, RME enabled greater number of lymph node harvest along recurrent laryngeal nerve (4.8 vs. $4.1 ; \mathrm{P}=0.012)$ at the cost of a higher incidence of recurrent nerve injury (29.2\% vs. $15.1 \% ; \mathrm{P}<0.001)$. Tumor recurrence occurred in 30 patients who underwent RME, among whom 9 (3.5\%) had locoregional recurrence only, 17 (6.7\%) had systemic recurrence only, and 4 (1.6\%) had combined recurrence. Meanwhile, only 26 patients who underwent TLME developed tumor recurrence, among whom 10 (10.6\%) had locoregional recurrence only, 7 (2.8\%) had systemic recurrence only, and 9 (3.6\%) had combined recurrence. The rate of mediastinal lymph node recurrence was significantly lower in patients who underwent RME ( $2.0 \%$ vs. $5.3 \% ; \mathrm{P}=0.044)$. However, given that the difference between RME and TLME could be attributed to the type of thoracic approach, the advantage of the robotic abdominal approach over the conventional laparoscopy seems to remain unknown. A multi-institutional, singlearm prospective study showed that robotic gastrectomy better reduced severe postoperative morbidity (ClavienDindo Grade $\geq$ IIIa) compared to laparoscopic gastrectomy as historical control among patients with cStage I/II gastric cancer (17). However, one should consider the substantial difference between gastrectomy for gastric cancer and gastric mobilization for esophageal cancer in terms of organ/vascular (right gastroepiploic artery) preservation for subsequent reconstruction, which requires extra caution resulting in slowing down the greater curvature procedure (18).

In summary, it remains unclear which type of abdominal approach is optimal when combined with robotic esophagectomy. Thus, future well-designed prospective studies are anticipated to address this question.

\section{Acknowledgments}

Funding: None.

\section{Footnote}

Conflicts of Interest: All authors have completed the ICMJE uniform disclosure form (available at http://dx.doi. 
org/10.21037/jtd.2020.03.124). The authors have no conflicts of interest to declare.

Ethical Statement: The authors are accountable for all aspects of the work in ensuring that questions related to the accuracy or integrity of any part of the work are appropriately investigated and resolved.

Open Access Statement: This is an Open Access article distributed in accordance with the Creative Commons Attribution-NonCommercial-NoDerivs 4.0 International License (CC BY-NC-ND 4.0), which permits the noncommercial replication and distribution of the article with the strict proviso that no changes or edits are made and the original work is properly cited (including links to both the formal publication through the relevant DOI and the license). See: https://creativecommons.org/licenses/by-nc-nd/4.0/.

\section{References}

1. Cuschieri A, Shimi S, Banting S. Endoscopic oesophagectomy through a right thoracoscopic approach. J R Coll Surg Edinb 1992;37:7-11.

2. Cuschieri A. Thoracoscopic subtotal oesophagectomy. Endosc Surg Allied Technol 1994;2:21-5.

3. Zhou C, Zhang L, Wang H, et al. Superiority of minimally invasive oesophagectomy in reducing in-hospital mortality of patients with resectable oesophageal cancer: a metaanalysis. PLoS One 2015;10:e0132889.

4. Yibulayin W, Abulizi S, Lv H, et al. Minimally invasive oesophagectomy versus open esophagectomy for resectable esophageal cancer: a meta-analysis. World J Surg Oncol 2016;14:304.

5. Biere SS, van Berge Henegouwen MI, Maas KW, et al. Minimally invasive versus open oesophagectomy for patients with oesophageal cancer: a multicentre, open-label, randomised controlled trial. Lancet 2012;379:1887-92.

6. Straatman J, van der Wielen N, Cuesta MA, et al. Minimally invasive versus open esophageal resection: three-year follow-up of the previously reported randomized controlled trial: the TIME Trial. Ann Surg 2017;266:232-6.

7. Kataoka K, Takeuchi H, Mizusawa J, et al. A randomized Phase III trial of thoracoscopic versus open esophagectomy for thoracic esophageal cancer: Japan Clinical Oncology Group Study JCOG1409. Jpn J Clin Oncol 2016;46:174-7.

8. Mariette C, Markar SR, Dabakuyo-Yonli TS, et al. Hybrid Minimally Invasive Esophagectomy for Esophageal
Cancer. N Engl J Med 2019;380:152-62.

9. Bodner J, Wykypiel H, Wetscher G, et al. First experiences with the da Vinci operating robot in thoracic surgery. Eur J Cardiothorac Surg 2004;25:844-51.

10. van Hillegersberg R, Boone J, Draaisma WA, et al. First experience with robot-assisted thoracoscopic esophagolymphadenectomy for esophageal cancer. Surg Endosc 2006;20:1435-9.

11. Dapri G, Himpens J, Cadière GB. Robot-assisted thoracoscopic esophagectomy with the patient in the prone position. J Laparoendosc Adv Surg Tech A 2006;16:278-85.

12. Ruurda JP, Draaisma WA, van Hillegersberg R, et al. Robot-assisted endoscopic surgery: a four-year singlecenter experience. Dig Surg 2005;22:313-20.

13. van der Sluis PC, van der Horst S, May AM, et al. Robot-assisted minimally invasive thoracolaparoscopic esophagectomy versus open transthoracic esophagectomy for resectable esophageal cancer: a randomized controlled trial. Ann Surg 2019;269:621-30.

14. Na KJ, Park S, Park IK, et al. Outcomes after total robotic esophagectomy for esophageal cancer: a propensitymatched comparison with hybrid robotic esophagectomy. J Thorac Dis 2019;11:5310-20.

15. Nozaki I, Mizusawa J, Kato K, et al. Impact of laparoscopy on the prevention of pulmonary complications after thoracoscopic esophagectomy using data from JCOG0502: a prospective multicenter study. Surg Endosc 2018;32:651-9.

16. Yang Y, Zhang X, Li B, et al. Short- and mid-term outcomes of robotic versus thoraco-laparoscopic McKeown esophagectomy for squamous cell esophageal cancer: a propensity score-matched study. Dis Esophagus 2020;33:doz080.

17. Uyama I, Suda K, Nakauchi M, et al Clinical advantages of robotic gastrectomy for clinical stage I/II gastric cancer: a multi-institutional prospective single-arm study. Gastric Cancer 2019;22:377-85.

18. Zheng $\mathrm{Y}$, Zhao XW, Zhang HL, et al. Modified exposure method for gastric mobilization in robot-assisted esophagectomy. J Thorac Dis 2017;9:4960-6.

Cite this article as: Tsunoda S, Obama K, Nishigori T, Hisamori S, Sakai Y. Robotic gastric mobilization in robotic minimally invasive esophagectomy. J Thorac Dis 2020;12(7):34573459. doi: $10.21037 /$ jtd.2020.03.124 